Article

\title{
Exploring Institutional Transformations to Address High-End Climate Change in Iberia
}

\author{
Joan David Tàbara ${ }^{1, *}$ (D) , Francesc Cots ${ }^{1}$, Simona Pedde ${ }^{2}$, Katharina Hölscher ${ }^{3}$, Kasper Kok ${ }^{2}$, \\ Anastasia Lovanova ${ }^{4}$, Tiago Capela Lourenço ${ }^{5}$, Niki Frantzeskaki ${ }^{3}$ and John Etherington ${ }^{6}$ \\ 1 Institute of Environmental Science and Technology, Autonomous University of Barcelona, \\ Cerdanyola del Vallés, 08193 Barcelona, Spain; xesco45@hotmail.com \\ 2 Soil Geography and Landscape Group, Wageningen University and Research, Droevendaalsesteeg 3, \\ 6708 PB Wageningen, The Netherlands; simona.pedde@wur.nl (S.P.); kasper.kok@wur.nl (K.K.) \\ 3 Dutch Research Institute for Transitions, Faculty of Social Sciences, Erasmus University Rotterdam, \\ Burgemeester Oudlaan 50, 3062 PA Rotterdam, The Netherlands; holscher@fsw.eur.nl (K.H.); \\ n.frantzeskaki@drift.eur.nl (N.F.) \\ 4 Potsdam Institute of Climate Change Impact Research, Telegraphenberg, A31, 14437 Postdam, Germany; \\ lobanova@pik-potsdam.de \\ 5 Centre for Ecology, Evolution and Environmental Changes, Facultade de Ciências, Universidade de Lisboa, \\ 1749-016 Lisboa, Portugal; tcapela@fc.ul.pt \\ 6 Department of Political Sciences, Autonomous University of Barcelona, Cerdanyola del Vallés, \\ 08193 Barcelona, Spain; john.etherington@uab.es \\ * Correspondence: joandavid.tabara@uab.cat; Tel.: +34-93-5868777
}

Received: 15 December 2017; Accepted: 5 January 2018; Published: 11 January 2018

\begin{abstract}
Either meeting the UNFCCC Paris agreement to limit global average warming below the $2-1.5{ }^{\circ} \mathrm{C}$ threshold, or going beyond it entails huge challenges in terms of institutional innovation and transformation. This research describes a participatory integrated assessment process aimed at exploring the options, opportunities, necessary capacities and implications for institutional co-operation and innovation in the Iberian Peninsula under High-End Climate Change (HECC). Using in-depth interviews and a novel participatory research approach, different scenario narratives and pathways about the future of Iberia have been identified using Shared Socio-economic Pathways (SSPs). Special attention is given to the knowledge and policy options needed to implement cross-border organizational changes and co-operation mechanisms that would support the Integrated Climate Governance of the Tagus and Guadiana river basins. We show that a wealth of institutional innovation pathways and specific options and solutions exist not only to reduce GHG emissions (mitigation) and the negative impacts of climate change (adaptation), but, above all, to generate new forms of social-ecological system interactions aligned with sustainability (transformation). In particular, and depending on which scenario contexts unfold in the future in Iberia, different kinds of institutional and governance capacities and clusters of solutions may be needed in order to achieve transformation.
\end{abstract}

Keywords: institutional transformation; high-end climate change; Shared Socio-economic Scenarios (SSPs); Iberia; transboundary rivers; cross-border cooperation; participatory research appraisal; Integrated Climate Governance (ICG)

\section{Introduction}

Either meeting the UNFCC Paris agreement of staying below the $2{ }^{\circ} \mathrm{C}$ target of global warming (while aiming at $1.5^{\circ} \mathrm{C}$ ) with respect to preindustrial times or exceeding that threshold poses great challenges to the reconfiguration of current institutions. Present greenhouse gas (GHG) emissions 
trends, and the potential weakening of the actual Paris accord after the US exit, indicate that, unless urgent action is taken at local and regional level, trajectories characterized by high-end climate change (HECC) [1] will become increasingly plausible outcomes (http:/ / highendclimateresearch.eu/). In this context, anticipating which kinds of institutional options and capacities will be most conducive to support transformative solutions aimed at dealing with these new climate futures is becoming increasingly urgent [2-4].

The main purpose of this paper is to present an innovative participatory methodology that is designed to assess the knowledge needs, alternative future pathways and capacities of regional organizations and agents to promote institutional innovations capable of responding to the new challenges posed by HECC $[5,6]$. First, our exploration starts with the examination of the kinds of institutional arrangements that exist both in Portugal and Spain with regard to climate policy. In particular, we looked at the knowledge needs of the transboundary river basin and cross-border Euroregions of Algarve-Alentejo-Andalucia (Lower Guadiana river basin), and Extremadura-Alentejo Centro (Lower Tagus and Guadiana river basin). Second, four explorative scenarios were developed using a participatory appraisal approach congruent with a combined set of Shared Socio-economic Pathways (SSPs) [7] and Representative Concentrated Pathways (RCPs). The aim was to identify a series of pathways of transformative solutions that might be able to achieve a transformative vision of the world, based on the assumption that visions lie at the root of societal transformations. Thus, in order to trigger transformative thinking and appraisal [8,9], a normative future was formulated in a participative way in the form of a vision. The aim of the latter was not to identify where Iberia could be (a task done in the exploratory SSP scenarios), but where the key agents and actors involved in climate action would like to be even in the face of HECC.

Consequently, in conditions of HECC, learning how to develop new forms of institutional arrangements aligned with Integrated Climate Governance (ICG) becomes a very complex challenge, as does designing opportunity pathways and concrete options and solutions for transformation. IGC can be understood as an explicit mode of co-ordinated collective action explicitly aimed at supporting transformation [10]. This perspective is based on the need to support new forms of public engagement, policy instruments and transformative research capable not only of informing but also, in turn, of creating new institutional designs in a social learning mode. Hence, IGC is not only about assessing risks, impacts and vulnerabilities, but also and most importantly, it is concerned with designing opportunity pathways and concrete options and solutions for transformation. Through implementing concrete capacities for IGC, it should be possible to facilitate a transdisciplinary process for the exchange, integration and outreach of networks among multiple knowledge-holders [11]. This requires a robust representation of the relevant knowledge systems and networks capable of co-ordinating and implementing multiple solutions according to different emerging socio-economic situations. The present research aims at contributing to this knowledge base by describing the particular case of Iberia which is part of a larger research effort of the EU funded project IMPRESSIONS, described below, which also includes other cases in Hungary, Scotland, Europe and Central Asia.

\section{High-End Climate Change in Iberia}

\subsection{Social-Ecological and Political Context}

The Tagus and the Guadiana river basins are two of the five international river basins shared between Portugal and Spain in the Iberian Peninsula, which accounts for some of Europe's river basins most likely to be affected negatively by HECC. Increasing problems affecting these river basins include: the growing persistence of droughts and water shortages and their impact on water quality; conflicts derived from multiple uses-e.g., agriculture and urban demands versus ecological system restoration; and the impacts of phenomena such as tourism, rural depopulation and land abandonment [1].

Both Spain and Portugal have set up administrative systems for water management based on shared hydrological basin boundaries according to the EU Water Framework Directive (WFD). 
Each country has their own separate basin authorities responsible for the management of the water resources in the basin: in Portugal, the Tagus Hydrographical Region Administration and the Guadiana Hydrographical Region Administration, and in Spain, the Tagus Basin Authority and the Guadiana Basin Authority. Each hydrographical region has implemented their hydrological river basin plans. However, in Spain, both the central government and the Autonomous Communities (ACs) play a relevant role with regard water management, while in Portugal these competences are mainly shared between the central government and the above-mentioned Hydrographical Regional Administrations.

The Basin Councils and the Council of Users in Portugal and Spain have been the main participatory instruments to involve key stakeholders within the general national strategies prepared by their respective National Water Councils. The latter are made up of representatives from all relevant ministries, sectoral users, NGOs, regional authorities and technical bodies at national level. Besides traditional actors, such as the main agricultural organizations, power companies and hydraulic confederations, other groups have adopted a more active role in the last decades, such as academics, local groups, regional communities and environmental organizations [11].

With regard cross-border relations, in 1998 the Albufeira Convention was signed by Portugal and Spain - the full name of the agreement is: "Agreement on Co-operation for the Protection and Sustainable Use of Spanish and Portuguese Transboundary Basins"- the main objectives of which are to promote the good ecological status of the waters in the Portuguese and Spanish river basins and to promote the sustainable use of those waters; and to mitigate effects from floods, droughts and water scarcity. This Convention created the Conference of the Parts, the main actor in transboundary water management, together with many governmental and departmental transnational working groups. In fact, in both basins, their plans and latest reviews were prepared in a collaborative and consensual way following the requirement of the WFD. However, there are still some cultural, administrative and political impediments to be overcome if full co-operation between both countries is to be achieved [12].

In terms of sub-state regional co-operation, cross-border ties between Spanish ACs and Portuguese regions on both sides of the border were initiated at the beginning of the 1990s. They were institutionalized as a result of the "Protocols of Cross-Border Co-operation" (CCDR) endorsed by the regional government of Extremadura and the CCDR Alentejo (1992) and CCDR-Central Portugal (1995), and by the Andalusian government and CCDR-Alentejo (1995) and CCDR-Algarve (2001). Starting practically from scratch, these four Working Communities initiated a productive first stage of co-operation. The first projects and results began to take shape more recently under the protection of the successive INTERREG programs and the Spanish-Portuguese Cross-Border Co-operation Operational Program (POCTEP). The growing interest and positive achievements of these institutional arrangements of the five regions in broadening their co-operation led to the signing of two single co-operation agreements (2009 and 2010) and the fusion of the four former Working Communities into two: (1) the Euroregion Alentejo-Alentejo-Andalucia (EUROAAA) and (2) Euroregion Alentejo-Centre-Extremadura (EUROACE), which helped to operationalize their administrative structures and to promote a new opportunity space of co-operation between these regions (www.euro-ace.eu and www.euroaaa.eu). However, there are still several deficiencies in the way they operate $[13,14]$. The first and probably most important common limitation is their organisational structure, which is too dependent on regions and lacks the necessary level of autonomy and institutional stability to become a key knowledge and policy action broker in this domain. Indeed, the secretariats or operational units of both EUROAAA and EUROACE are inserted into the institutional frameworks of the Spanish and Portuguese regions, therefore lacking the autonomy to operate and to take decisions based purely on cross-border interests. Second, there is an excessive dependence on European funds as they are projects financed by the European Union and consequently subject to periodic decisions about their funding and existence. Third, these operational units clearly lack a number of both human and organizational resources needed to tackle the multiple difficulties associated with cross-border integration. Fourth, there is an asymmetry in power relations 
within the respective Spanish and Portuguese institutional settings, including limited interaction and co-ordination among national, regional and local entities. And last but not least, we have detected a notable absence of a strategic sustainability approach for these regions that is capable of clearly incorporating the precautionary principle and a broader ecosystem-based approach as key elements for fostering policies in this area [15]. This is manifested by the failure to incorporate climate change scenarios into those strategies.

\subsection{Research Process}

The present research is part of the EU project IMPRESSIONS (www.impressions-project.eu; Impacts and Risks from High-End Scenarios: Strategies For Innovative Solutions) which in Iberia had four main objectives: (1) To improve scientific understanding of the implications of High-End climate and socio-economic change; (2) To develop together with relevant stakeholders a series storylines on future socio-economic developments in Iberia under these conditions; (3) Work jointly with decision-makers to explore the development and implementation of innovative solutions to HECC in Iberia based on different plausible scenarios; and (4) Focus on innovative integrated resource management of the Tagus and Guadiana transboundary river basins under the potential of high-end climate scenarios.

A first task in the research process was to identify the knowledge needs of key policy makers both in Portugal and Spain regarding the potential implications of HECC in Iberia. For this purpose, the knowledge uses, the organizational capacities of the secretariats, and the establishment of horizontal and vertical collaborative institutional networks were examined. In addition, we analyzed the level of integration of climate change knowledge and adaptive water management objectives of the Tagus and Guadiana river basins into regional development under HECC. To this end, a total number of 26 interviews were conducted both in Portugal and Spain $[15,16]$.

Secondly, a participatory process was carried out entailing a series of professionally organized and facilitated workshops with key stakeholders in Spain and Portugal. Invited stakeholders were identified via a Stakeholder Mapping exercise using several categories of stakeholders (e.g., sectors, gender and age), a minimum quota for each category and the placing of each individual in the categories $[17,18]$. The stakeholder mapping exercise resulted in the inclusion of actors from Portuguese, Spanish, Andalusia and Extremadura governments, as well as non-governmental organizations, business associations, research institutes and transboundary institutions (from both Euroregion AAA and Euroregion ACE).

\subsection{Institutional Knowledge Needs to Confront HECC}

Regarding the knowledge and information that is currently required by Portuguese and Spanish decision-makers when facing the potential implications of HECC in Iberia, interviews on both sides of the border revealed both barriers and limitations in using climate and socio-economic information, including scenarios about HECC [16]. For example, results from the Spanish interviews pointed to the need to clearly differentiate, on the one hand, the information and knowledge required to elaborate general policy programming objectives that specifically address climate change and land use planning from, on the other, those programs or policies which do not do so. Examples of the former are the Andalusia and Extremadura climate adaptation plans as well as the Tagus and Guadiana river basins hydrological plans. In parallel, about half of the Portuguese participants (58\%) indicated that they did not systematically make use of future climate change information (HEEC or otherwise) or detailed climate impact model output in their decision-making processes. However, they acknowledged that climate change and impact scenarios are applied to the elaboration of specific plans (e.g., Tagus Basin hydrological plans) even if detailed quantitative data is not readily available for all specific variables of interest. They additionally reported the more widespread use of socio-economic trends, socio-economic projections and scenarios [16,19]. On the Spanish side a similar picture emerged regarding climate scenarios: public authorities recognized that the first 
step in setting policy objective takes little note of previous available analysis of climate data, models or similar tools. This was the case of the development of the cross-border co-operation strategy for the Algarve-Alentejo-Andalucía Euroregion.

In relation to the information content, the most commonly reported sources of climate change information, both in Portugal and Spain, are products from national research projects and the IPCC reports. Additionally, interviewees recognized that most regional processes include some sort of participation of experts and representatives of civil society. However, respondents also pointed out the lack of salient data. When questioned about the existing limitations of the use of climate change (HECC or otherwise) information for decision-making, they also mentioned that the key issue was not so much the uncertainty about data related to HECC, but the actual lack of such information. Last but not least, both Portuguese and Spanish agents reported low levels of HECC information use, mentioning an interest in having that sort of data available and contextualized at both local and regional levels, albeit noting that this availability would not necessarily translate directly into its use for policy development or programming of different land use objectives.

\subsection{The HECC Participatory Integrated Assessment Process}

\subsubsection{General Design}

The engagement process was divided into three workshops following a sequence of tasks aimed at: (1) Creating a series of plausible futures for Iberia in the form of narratives [20], using a process of participatory downscaling of the global Shared Socio-economic Pathways (SSPs) [19] linked to high-end climate scenarios (beyond $2{ }^{\circ} \mathrm{C}$ by the end of century) [21,22] that were, in turn, based on Representative Concentrated Pathways [RCPs] [23]; (2) Developing a common vision on where Iberian stakeholders would like to be by the end of the century; (3) Providing alternative pathways of solutions to achieve that vision and prevent HECC; and (4) Assessing such solutions and pathways to identify those with more transformative and institutional innovation potential (Figure 1). Out of a set of plausible future outlooks, the stakeholders developed four socio-economic scenarios about what could happen, then a vision about what they would like to happen, and, lastly, strategies and actions included in pathways to reach the vision in the context of integrated climate and socio-economic scenarios. In between the workshops, scientists sought to review their analyses with stakeholders to ensure legitimacy and saliency, and assessed the potential of different pathways to achieve the vision.

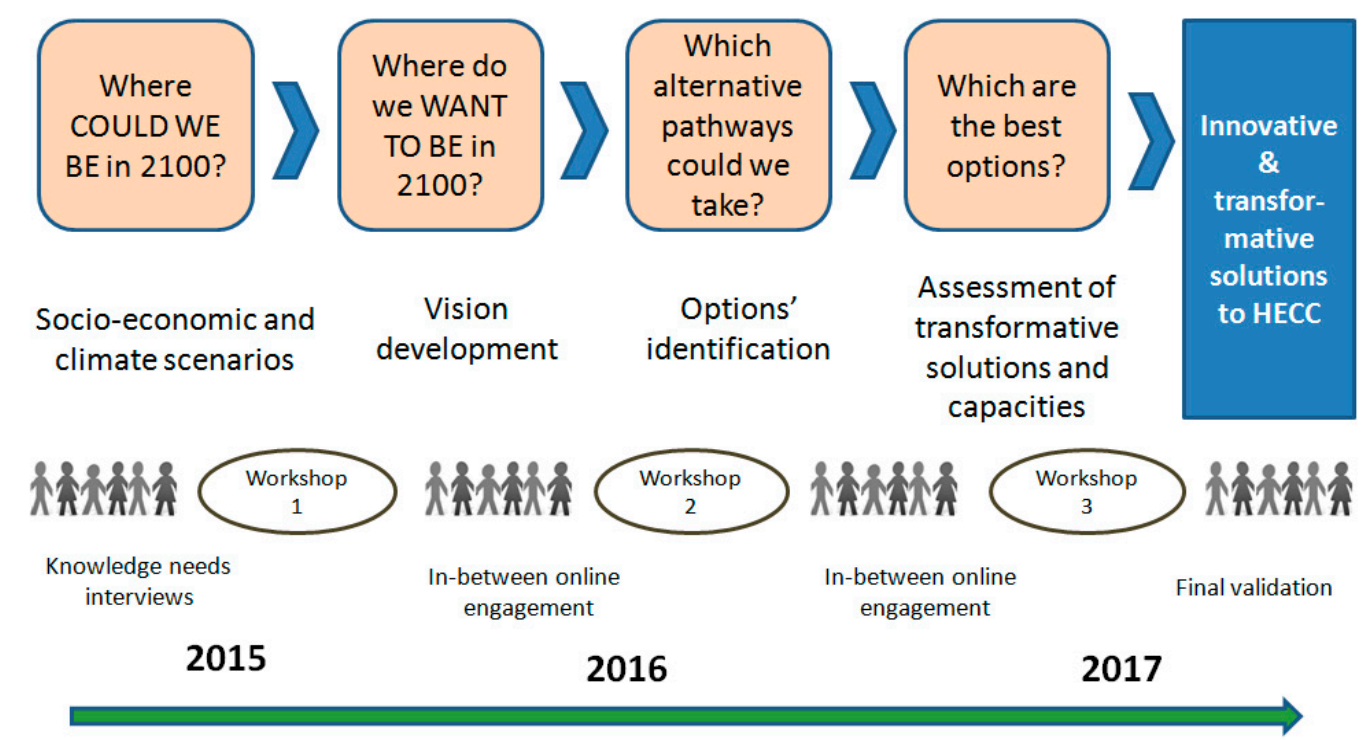

Figure 1. Process of stakeholder engagement in Iberia: from the development of socioeconomic and climate scenarios to identifying innovative solutions to HECC. 
The combination of exploratory scenarios, models, pathways, visions and solutions, co-produced in a participatory setting, is one of the novel and original contributions of this methodology. However, the approach was not without problems. On the one hand, it was not easy to downscale global and European SSPs onto the regional level and to integrate the modeling results into them. On the other, there were difficulties regarding more operational issues, such as bringing Spanish and Portuguese stakeholders together, which introduce additional obstacles that are not necessarily related to language or culture but rather to specific issues and preferences in the topics addressed.

\subsubsection{Socio-Economic and Climate Scenarios}

The stakeholders thus contributed to the downscaling of four socio-economic scenarios in the context of high-end climate change. In particular, narratives and tabular overviews of key elements were presented to stakeholders as starting points for socio-economic scenario development for Iberia. Quantitative model variables (e.g., population and GDP) were used as model inputs. RCPs served as inputs to global and European climate models. Climate change impacts were calculated by combining socio-economic and climate scenarios. SSPs were downscaled from global and European scenarios, and models used both sources to project future climate change impacts. In the first workshop, stakeholders determined the content of four exploratory socio-economic scenarios in the region, i.e., structuring four plausible scenario narratives in answer to the question "what could happen in Iberia from now to 2100" (Figure 1). The facilitated co-production process [17] ensured that the scenarios were embedded in a broader global and European context shaped by the SSP $\times$ RCPs narratives and datasets $[23,24]$. The European SSPs provided the context along with the main uncertainties regarding inequality and carbon intensity (Figure 2), which are consistent with the global SSP uncertainties on the challenges to adaptation and mitigation scenarios [7] in the context of the wider uncertainties related to sustainability. Our research focused on socio-economic scenarios given that we understand that such future contexts frame the conditions and driving forces from which various climate futures may emerge. The resulting socio-economic scenarios are sketched in Figure 2 [19].

The Iberian narratives were co-constructed based on the stakeholders' input and researchers' interpretations, later validated by the stakeholders themselves. The following SSPs emerged:

\section{Iberia SSP1—Sustainability}

Triggered by continuing and growing social participation in environmental, social and economic issues, and fueled by a European social-oriented political framework, Iberia embraces a path towards a new development model. From slow beginnings, socially- and environmentally-sustainable policy making encourages an increasingly rapid and fundamental change, boosting education, innovation, job opportunities in the green sectors (renewable energies and reuse of materials), and eventually green technologies. Because of the strengthening of democratic governance structures, globalization is no longer opposed to local sustainability; on the contrary, positive sustainable development synergies are created. This leads also to an economic shift in many sectors, whereby technological development and high-value exports become the new backbone of the Iberian economy. By 2100, the new decision-making culture and practice culminates in the new development model for the Iberian countries. This model encourages broad public participation, institutional collaboration and includes the harmonic integration of health, social, economic, political and environmental sectors. 


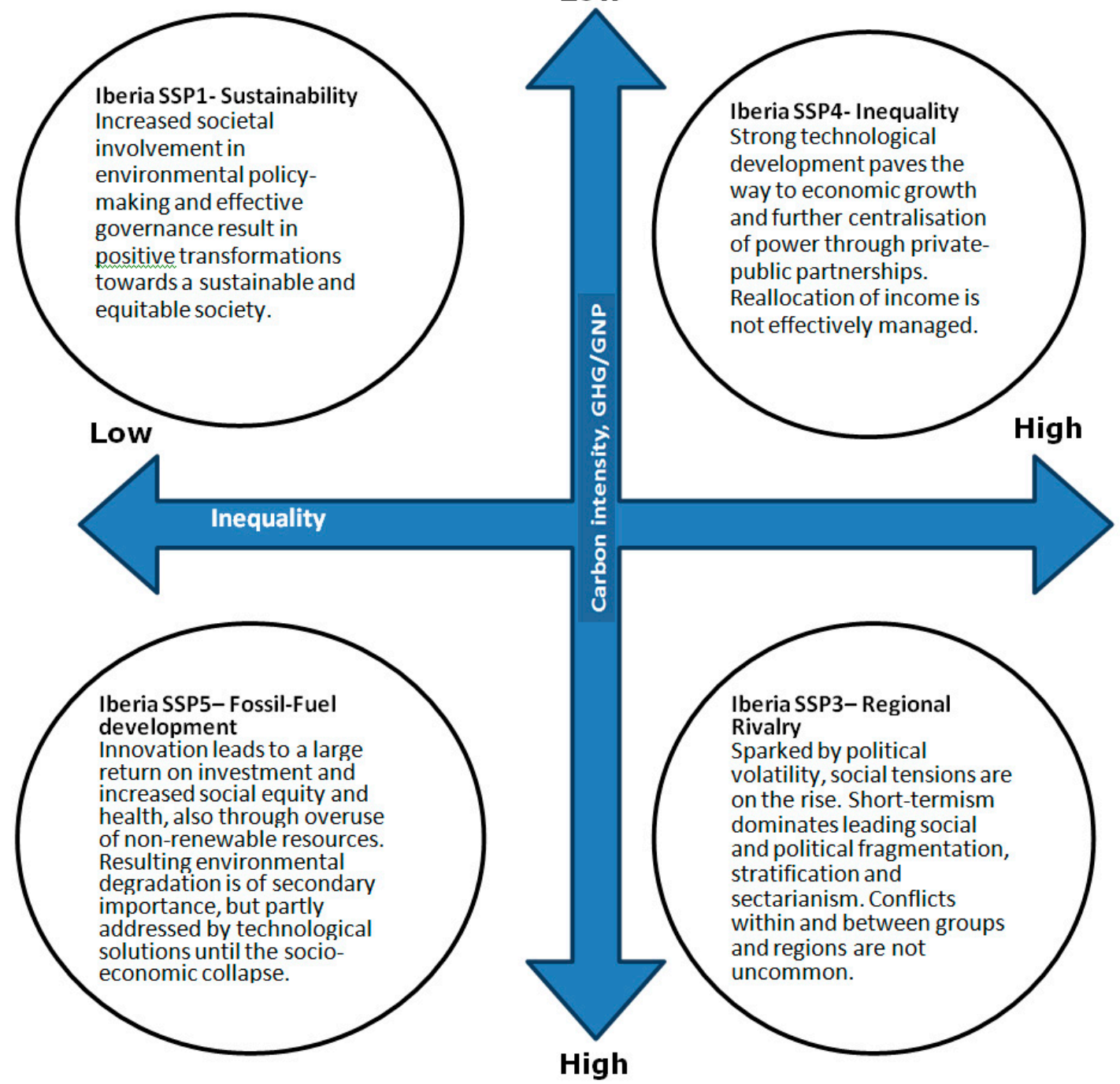

Figure 2. Sketch of four Iberian socioeconomic scenarios (SSPs) positioned along the uncertainties on inequality and carbon intensity [19].

\section{Iberia SSP3—Regional Rivalry}

Short-lived governments lead to a fragmentation of the social and economic fabric in Iberia. In 2030 Catalonia gains independence, which is later followed by other regions both in Iberia and in other Mediterranean countries. To counteract economic crises, the Southern countries create a separate Union, the "Club Med". Continued environmental and economic problems increase social tensions and social inequalities, which in turn negatively affect tourism. By the 2060s four independent countries have come to exist in Iberia: Portugal, Spain, Catalonia and the Basque Country, with strong borders between them. Over time, conflicts escalate, although war over water and other scarce resources is prevented. By 2100, a deserted and desertified inland rural Iberia remains, producing a greater division within Iberia than between Iberia and the rest of Europe. Elsewhere, continuous conflicts also occur across multiple countries which experiment similar disintegration processes elsewhere and this limits co-operation within Club Med and with other international power blocs. 
Iberia SSP4-Inequality

Economic challenges and environmental accidents are exacerbated by new European and global crises, which leads to increased migration from Northern Africa and the Middle East. In Iberia, unemployment rises to record levels and eventually results in social unrest and massive protests. Social stratification intensifies with strong high-income elites and a large divided lower class, bringing about strong tensions within and between social classes. This unstable social situation escalates in the 2040s, and leads to a shift in the political system. New governments establish an oligarchic system with power and money gradually centralized and controlled by an elite of a few companies and central governments. The political and industrial elite successfully implements a strategy of "subtle" enforcement of inequality through education and keeping people employed in low skilled jobs, with low future expectations. For their own benefit, the elite invest in solar and wind energy, eventually becoming a market leader.

Iberia SSP5—Fossil-Fueled Development

The bursting of the financial bubble increases the need for social aid and subsidies for Iberia, which is facilitated by an increasing economic surplus in the north of Europe. Central to this is the establishment of a connection of power networks that increase access to external (fossil) resources. Iberia is part of this network and located strategically in the energy nexus. Iberia also starts exploiting its own resources, while intensifying agriculture and forestry. In the 2040s, environmental problems occur that are dealt with successfully by using technological solutions. The accompanying environmental destruction goes by unnoticed as most people live in the cities, where water, food, and energy supply are secured. By 2060, Iberia is totally dependent on technology, fossil fuels, and the investments of large companies. Ultimately, a number of environmental disasters lead to an increased awareness across Iberia that technology can no longer sustain agricultural production. The outlook is uncertain as the fossil fuel-based development model collapses and business opportunities decrease.

\subsubsection{Vision Development}

A normative future was created in a participative way in the form of a vision, by asking stakeholders "where do we want to be in Iberia 2100?".

In contrast to the four exploratory scenario narratives of "the future we could have", the vision showed an explicitly normative depiction of "the future we want". The vision was thus developed to trigger thinking on long-term target setting while at the same time guiding short-term and mid-term action and strategies $[20,25]$. The vision was also created through an iterative participatory process. First, the stakeholders were asked in a survey to describe elements of their "vision for Iberia in 2100". Sixteen contributions were collected, which were then sorted and categorized into common vision themes to structure the input as well as to identify possible disagreements and missing elements. Subsequently, the stakeholder input was combined into a vision narrative. A shorter version of the vision was visualized in a poster (Figure 3). Both the narrative and the poster were presented at the second stakeholder workshop to verify and enrich the vision, which resulted in an updated version of the vision.

The following vision components were identified:

"Iberia in 2100"

- "Iberia supports greater global co-operation and solidarity, with respect for human rights and distinct identities of people" (Co-operation and identity).

- "Iberia is a coherent, diverse and peaceful territory co-ordinated by transparent Iberian governmental institutions and a highly politically-engaged society" (Governance). 
- "All people in Iberia have access to public services and social support, engage in sustainable, community-based lifestyles aligned to context-specific needs and opportunities" (Health, wellbeing and sustainable lifestyles).

- "Sustainable natural resource management and resource protection is ensured through strict policies" (Protecting the environment).

- "Cities are smaller, self-sufficient in terms of energy production, provide space for social activities, and promote sustainability throughout their respective hinterlands" (Sustainable urban planning and land use).

- "The use of Iberian natural resources yields minimum impact on natural ecosystems and is balanced with the maximum reuse, recycling and recirculation of materials" (A sustainable and local economy).

- "Sustainable food and water management and 100\% renewable energy production go hand-in-hand with more conscious consumption and access to quality food and water" (Food, water and energy).

- "There is a guaranteed access to education that supports professional, social and practical skills and technological innovation, as well as full employment and fair income distribution" (Income, education and jobs).

- "Adaptation plans and quick response strategies have been deployed to cope with climate change and extreme events" (Resilience).

Thus, regarding governance, it was stressed that one possibility to facilitate the move to a better-off socio-economic situation to cope with HECC would be the creation of a kind of unified Iberian government to articulate common actions and interests while respecting the rich cultural diversity of the Iberian Peninsula.

\subsubsection{Solutions and Pathways}

After the vision formulation, the stakeholders were asked to identify innovative solutions that would enable the achievement of their long-term vision in the context of the different exploratory integrated scenarios. The formulated solutions were clustered according to themes identified by the stakeholders (e.g., education, water management, agriculture) and time-stamped from the present to 2100. In this way, a suit of pathways consisting of time-dependent strategies was generated in Iberia in different SSPs as follows (see Table 1):

Table 1. Different pathways identified in Iberia in the four downscaled Shared Socio-economic Pathways (SSPs).

\begin{tabular}{ccccc}
\hline Pathway & SSP1 & SSP3 & SSP4 & SSP5 \\
\hline $\begin{array}{c}\text { Promote integrated and collaborative water } \\
\text { management and sustainable water use }\end{array}$ & $\sqrt{ }$ & $\sqrt{ }$ & $\sqrt{ }$ & $\sqrt{ }$ \\
\hline Promote shifts to sustainable lifestyles & $\sqrt{ }$ & $\sqrt{ }$ & $\sqrt{ }$ & $\sqrt{ }$ \\
\hline Promote ecological agriculture & $\sqrt{ }$ & $\sqrt{ }$ & $\sqrt{ }$ & $\sqrt{ }$ \\
\hline $\begin{array}{c}\text { Promote democratic and multi-level } \\
\text { governance for sustainability and social equity }\end{array}$ & $\sqrt{ }$ & & $\sqrt{ }$ \\
\hline $\begin{array}{c}\text { Promote shifts towards low-carbon and local } \\
\text { energy systems and markets }\end{array}$ & $\sqrt{ }$ & $\sqrt{ }$ & $\sqrt{ }$ & \\
\hline
\end{tabular}



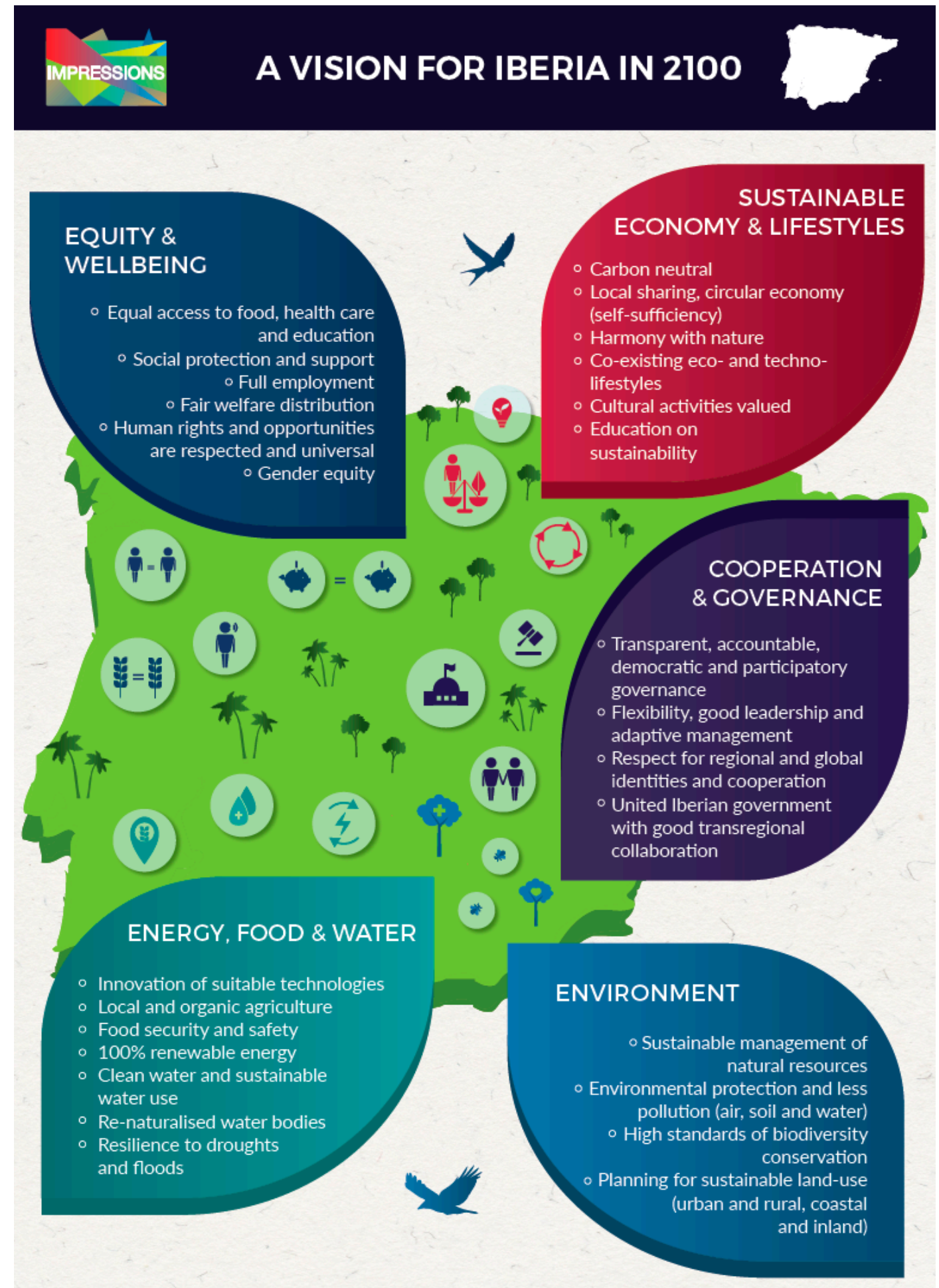

Figure 3. Iberian Vision in IMPRESSIONS.

- $\quad$ Promote integrated and collaborative water management and sustainable water use: All scenarios include a pathway to promote integrated and collaborative water management and sustainable water use. This is an adaptation pathway that ensures water quality and water quantity and climate adaptation. The pathway addresses the vision elements on "food, water and energy", "resilience" and "governance". It also establishes integrated and holistic water management 
strategies and approaches for Iberia that protects water quality and quantity, adapts to climate change and ensures equal access to water. It also calls for innovative water infrastructures and technologies to improve efficiency in water use, protect water quality and adapt to climate change and for the setting up participatory, multi-level and transboundary water governance systems to manage and control water use and water quality and quantity. In addition, strong regulations, standards and incentives are to be put in place to promote sustainable water use, water efficiency innovation and water monitoring systems in line with ecological flows.

- Promote shifts to sustainable lifestyles: All scenarios include a pathway to promote a shift towards sustainable lifestyles, which involves the transition to sustainable production and consumption patterns and behaviors, and major changes to the education system. This is a transformation pathway that involves fundamental shifts in values, behaviors and practices. The pathway addresses vision elements on "health, well-being and sustainable lifestyles" and "income, education and jobs". It also sets up a new education system to which everyone has access and that integrates education about sustainability, solidarity, traditional knowledge, skills and entrepreneurship. Education is provided and targeted for all age groups and to intergenerational groups for solidarity; environmental and social education is integrated in schools; there is significant investment in environmental and social research and includes awareness-raising activities to promote awareness on self-sufficient lifestyles, energy efficiency, food waste reduction, intermodal mobility, climate change, water savings and reuse, and different diets. The SSP3 and SSP4 pathways facilitate social cohesion and protect social and human rights, while the SSP1 and SSP5 pathways create alternative community-based markets. New markets are set up at the local level with job sharing. Alternative trading systems are put in place such as local currencies and time banks. Local renewable energy is promoted for self-sufficiency.

- Promote ecological agriculture: This pathway develops integrated policy frameworks for ecological agriculture that are adapted to ecological and context-specific needs and conditions and to climate change. The pathway shifts towards ecological agricultural practices to adapt agriculture to climate change impacts and land and water availability. Conservation agriculture is implemented. It includes a shift towards agro-forestry and sustainable forestry and supports technological innovation to facilitate ecological agriculture and protect water quality and quantity. This pathway puts in place regulations, standards and incentives to promote ecological agriculture and the shift towards integrated land use management and the training of farmers in ecological agricultural practices, which in turn also contributes to rural development and social cohesion.

- Promote democratic and multi-level governance for sustainability and social equity: SSP1, SSP4 and SSP5 include a pathway to promote policy and governance for sustainability and social equity. This is a transformation pathway that involves fundamental shifts in the ways the governance system is set up to enable multi-level cooperation, transparency and participation in line with long-term and integrated sustainability and resilience goals. The pathway addresses vision elements on "governance" and "co-operation and identity". Iberia develops integrated environmental protection frameworks and policies that integrate nature into market and planning activities and fit policies to specific regional conditions to harmonize social and economic development in line with environmental conditions and climate change. A democratic, fair and transparent governance system is ensured, public participation is increased and political power is decentralized. NGOs are encouraged to take an active role in decision-making and engaging people. The pathway sets up collaborative and multi-level governance across scales and sectors. Participation forums are established all the way from schools to parliaments. Social networks and enterprises and political activism are fostered to ensure broad participation and social collaboration. The SSP5 pathway puts in place monitoring systems to ensure that decision-making is supported by science and to measure individual consumption in agriculture.

- Promote shifts to low-carbon and local energy systems and markets: SSP1, SSP3 and SSP4 include a pathway to promote shifts to low-carbon and local energy systems and markets to support 
urban and rural development. This is a mitigation pathway that includes technological innovation for renewable energy production on local and regional levels and for energy and resource efficiency. The pathway addresses vision elements on "food, water and energy" and "sustainable and local economy". The pathway invests in a diversified local economy that is adapted to context conditions, promotes production and consumption based on local resources and creates local jobs. Local markets are created based on local resources for production, waste, water, energy and services. It develops green technological innovations to increase energy efficiency and achieve self-sufficient renewable energy production. The implementation of renewable energies and decreasing energy consumption is incentivized and enforced through subsidies and regulations. Iberia divests from fossil and nuclear energy and the implementation of green energy is made compulsory. An annual carbon budget is established and carbon taxes based on real carbon costs are introduced. For example, a carbon tax on tourism is established.

In this paper, we focus on those pathways related to water and ecosystems management and institutional change with special attention to cross-border governance and co-operation. Our results showed that pathways in all scenarios stressed the need to support integrated water management [26,27] in a way that enhances climate resilience and builds on collaborative and transboundary governance institutions, policies and regulations [28]. This is supported by other pathways that promote shifts towards sustainable lifestyles, including socially responsible attitudes towards water, and strong environmental policies for other sectors, especially agriculture, infrastructure modernization and technology innovation.

However, the implications for transboundary collaboration of water and development policies differ across the various pathways for the scenarios, with some focusing more on mitigation, adaptation or, more broadly, on societal transformation and institutional innovation. Within the "Sustainability" scenario (SSP1) and the "Fossil-fueled Development" scenario (SSP5), the opportunities and capacities derived from strong governance institutions are utilized to implement new water monitoring systems and to introduce water taxes and other fiscal measures. In this scenario, subsidies to reduce water use and education initiatives to promote awareness about responsible water use are implemented. In the "Inequality" scenario (SSP4), a central element to achieve integrated water management is the strengthening of collaboration and co-ordination processes through trade agreements and protocols between Portugal and Spain — to be regularly reviewed and updated—and common agencies to monitor and protect water resources. The strengthening of transboundary collaboration with an overseeing transboundary organization that coordinates the agreements and protocols was also proposed. In the "Regional Rivalry" scenario (SSP3), the focus of the pathways was on minimizing the institutional and social fragmentation in Iberia. In this scenario, and to ensure and co-ordinate co-operative water and river-basin management, a transboundary policy platform is set up for actors from the different governments and the public to share knowledge and to decide on joint policies to protect water from a cross-sectoral perspective.

Solutions promoted in each scenario were slightly different from each other. For example, the pathways for SSP4 considered water in relation to land-use planning and emphasized an equitable distribution of water resources. Solutions to achieve this include the implementation of conservation policies for natural areas to protect water resources, instantaneous flow measuring as well as the implementation of policies promoting equality. In both SSP1 and SSP3 solutions tended to focus on local levels with special attention within SSP1 on putting in place modernized water infrastructure, while in SSP3 stated solutions include increased water storage, water re-use and desalination, and adapting crops to changing local conditions. A further description of some of the transformative proposals for Iberia within the four SSP scenarios as described by the stakeholders in the third workshop in a session on "game-changing options" is shown in Table 2. Note that the different solutions or options are not to be considered better or worse from other options but only deemed to be better fit for purpose as 'game-changers' to attain the vision in the different socio-economic scenarios. Or in other words, there is no necessarily one single solution that can be applied in all the socio-economic contexts in the same way but in a situation of high uncertainties such as in HECC, different kinds of transformative 
solutions and institutional innovations may need to be taken into account. Notwithstanding, and as a robust result from the participatory process, the pathways in all socio-economic scenarios supported strategies and solutions aimed at an integrated, transboundary and cross-scale management of water resources that is supported by enhanced Iberian institutional co-operation. What differs among them is that each scenario context implies different types of institutional and governance capacities to adapt the different solutions to different contexts, e.g., more top-down and strategic in SSP3 and more bottom-up and local in SSP4, more or less integrated with different science, research and technology development options.

\subsubsection{Modeling Results}

A series of modeling results explored the risks posed by high-end climate change to land and water resource management including agro-forest systems and governance of transboundary river basins. By addressing climate change impacts and vulnerabilities within the Tagus river basin, the case study aimed at exploring which structural conditions and capacities can lead to positive fundamental systemic responses. The modeling framework was provided by the SWIM model described in detail in the work of Lobanova et al. [29]. The objective was to support decision-makers in incorporating high-end climate change scenarios into their risk management strategies and co-ordination mechanisms for shared water resources and sensitive social-ecological systems. High-end climate change impacts and adaptation were explored under four socio-economic scenarios that have been co-created with stakeholders drawn from a diversity of Portuguese and Spanish organizations. Original results presented here are based on combinations of four Iberian Shared Socio-economic Pathways (SSP) and two representative concentration pathways (RCP): (i) SSP1/RCP4.5; (ii) SSP3/RCP8.5; (iii) SSP4/RCP4.5; (iv) SSP5/RCP8.5.

- There are projected decreases in the overall water availability in the Tagus river basin, under all scenarios, by 2071-2100 (Figure 4): The modeling results for Iberia project significant changes in annual and seasonal precipitation, with uncertainties on both the strength of the change and its seasonal variations. From these results it is evident that the Iberian Peninsula and the Tagus River basin area in particular will continue on their current trend towards a drier and more vulnerable landscape. Seasonal variability is expected to play a major role in the socio-economic outcomes under HECC scenarios, since current water resources and agroforestry management in that area are highly dependent on accumulated precipitation during the hydrological year (October to September), in particular during the wet period (October to April).

- The operation of the water management infrastructure (based on the example of the headwaters of the Tagus river catchment) will be strongly affected by the decreasing water availability under both RCP4.5 and RCP8.5, but results are dependent on the socio-economic narrative that is followed (Figure 5): When following the SSP1 $\times$ RCP4.5 narrative it is possible to impose and sustain the environmental flows in the river and increase the adaptive capacity of the two reservoirs in the headwaters of the river Buendía and Entrepeñas. However, in this case the water supply for the economic needs (to Segura River Basin, via Tagus Segura Water Transfer) has to be substantially decreased. Under the SSP3 $\times$ RCP8.5 scenario, even in the case of complete negligence towards the environmental state of the river (imposing constant minimum water flow), the economic needs aspired cannot be reached, due to dramatic decrease in the water availability. This situation also leads to significant decrease of the water volumes, stored in the reservoirs due to combination of water management strategies and effects of climate change. 
Table 2. A selection on specific options to support 'game-changing' transformations in Iberia according to different SSP scenarios as mentioned by the third Iberian workshop stakeholders.

- Reconfigure, downsize but avoid the sprawl of cities and infrastructures. Make Cities energetically self-sufficient; install photovoltaic energetically self-sufficient; install photovoltaic
energy on buildings to feed transport networks.

- Make local currency and Time Banks availableIncentivize new models of goods and service exchange at a small scale

- Put taxes for carbon and water

Develop technologies to make crops more climate resilient.

- Reduce the need for commuting and develop new forms of work and time organization

- Promote deep changes in World trade towards fair trade
- Promote local and circular economy, e.g., by boosting the cooperative movement a institutional/organization innovations to make local and circular economy feasible

- Allow local currencies, the non-monetary exchange of products, exchange of time and time banks

- Support quality education and training

Enhancement of passive houses (of zero emissions).

- Promote bicycle use, walking, and low carbon transport

- Promote Industry 4.0, by digital eco-transformation of manufacturing

- Creation of a market eco-label for

Iberian Dehesa/Montado eco-landscape products - Promote cross-border business collaboration to
support eco-innovation
In agricultural and food systems, promote integrated land and agricultural management and urban food production

- In governance, develop legislation that support

sustainable communities

- In energy systems develop green unusual alternative energies

- In residential sector, promote households without emissions and with ample use of biomass

- In transport systems develop efficient no pollution
- Promote institutional transformations that lead to local energy communities

- Support networks that allow to increase resource efficiency and reduce costs

- Promote transformations in the way people we work and use their time: work less hours to have more work for more social interactions and people Promote green technologies such as desalination which are also cost-effective 

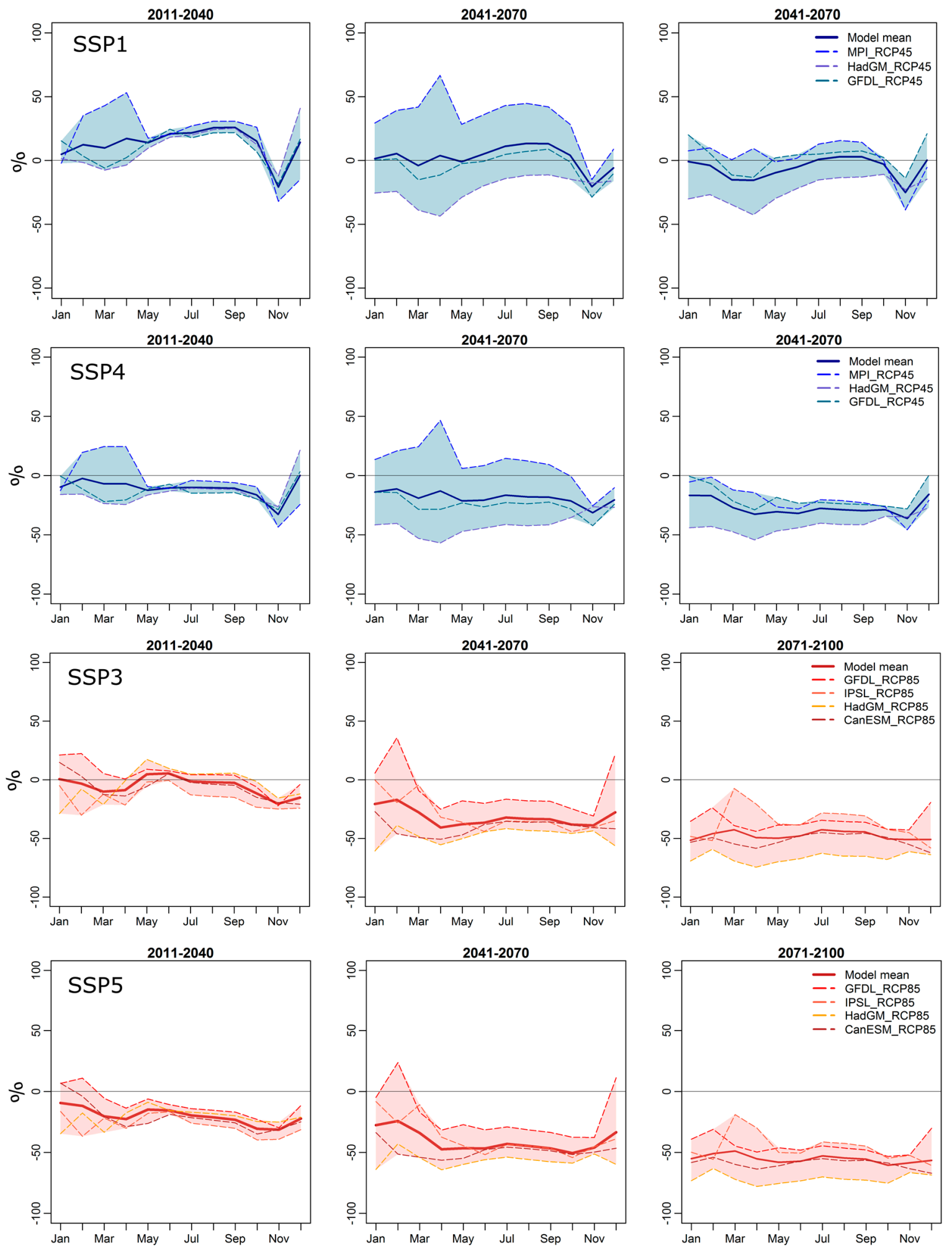

Figure 4. Discharge deviation at the outlet of the Tagus River Basin under the RCP4.5 $\times$ SSP1 (first row), RCP4.5 × SSP4 (second row), RCP8.5 × SSP3 (third row), and RCP8.5 × SSP5 (fourth row) scenarios, for three time slices 2011-2040 (left column), 2041-2070 (middle column), 2071-2100 (right column) relative to the reference period 1981-2010. 

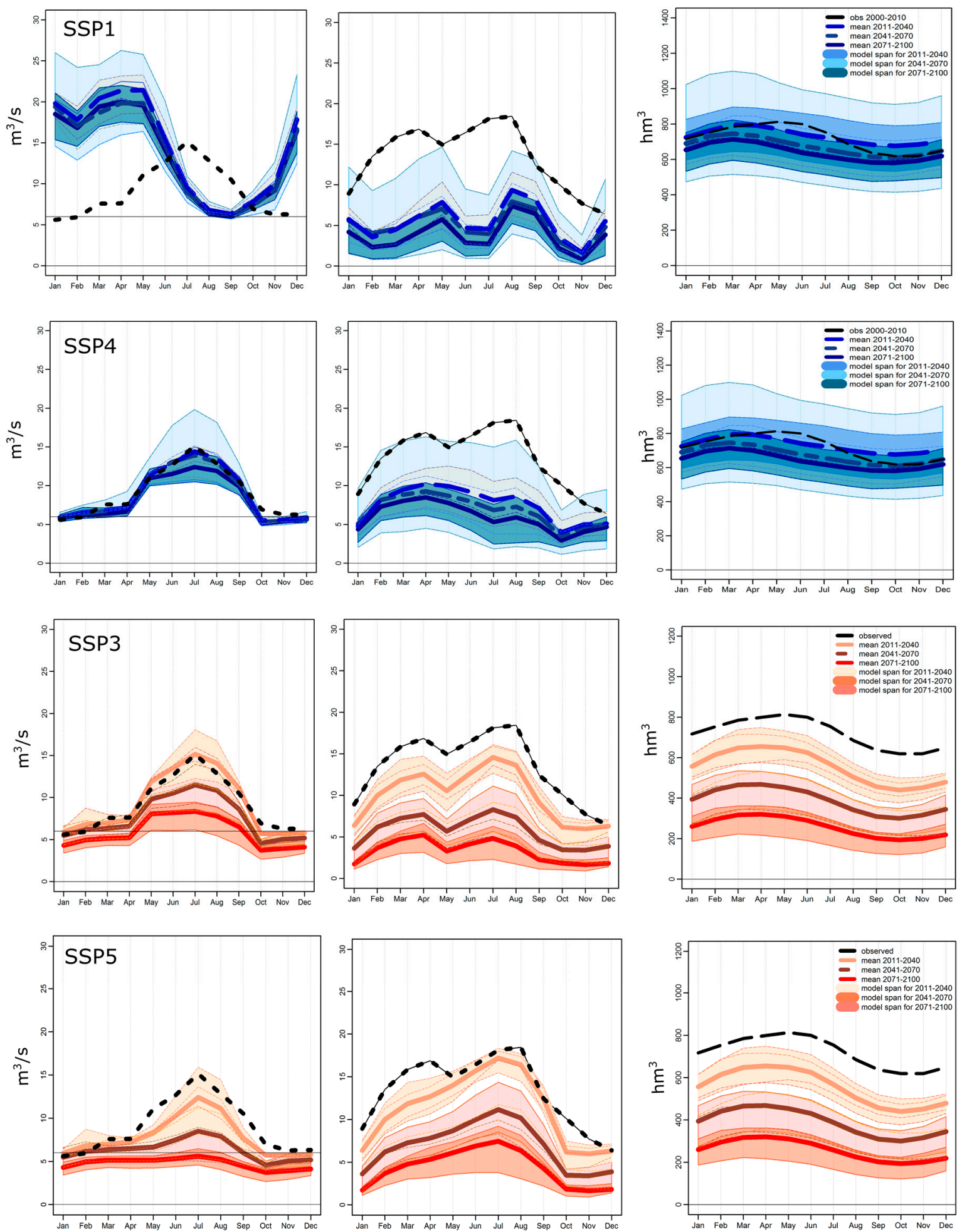

Figure 5. Long-term mean monthly discharge projections in the Tagus river under the RCP4.5 $\times$ SSP1 (first row), RCP4.5 $\times$ SSP4 (second row), RCP8.5 $\times$ SSP3 (third row), and RCP8.5 $\times$ SSP5 (fourth row) scenarios, after the Tagus Segura Transfer extraction (left column); of water supplied to the Segura Basin (middle column); and volume of the Buendía and Entrepeñas reservoirs (right column). 


\subsubsection{Potential of Pathways to Achieve the Vision}

In addition, IMPRESSIONS developed an innovative methodology combining expert judgment and modeling tools for assessing the efficacy of the pathways in meeting various components of the Vision in the context of high-end scenarios. In particular, the methodology subdivides the Vision into case-study specific indicators that, depending on the availability of appropriate modeling tools, allow the objective setting of a target value (quantitative analysis) or state (qualitative analysis) for each component. The potential efficacy of adaptation, mitigation and transformative actions in each of the pathways in moving the scenario closer to achieving the Vision is then assessed considering both scenario constraints and resource availability (capital) limitations (Figure 6).
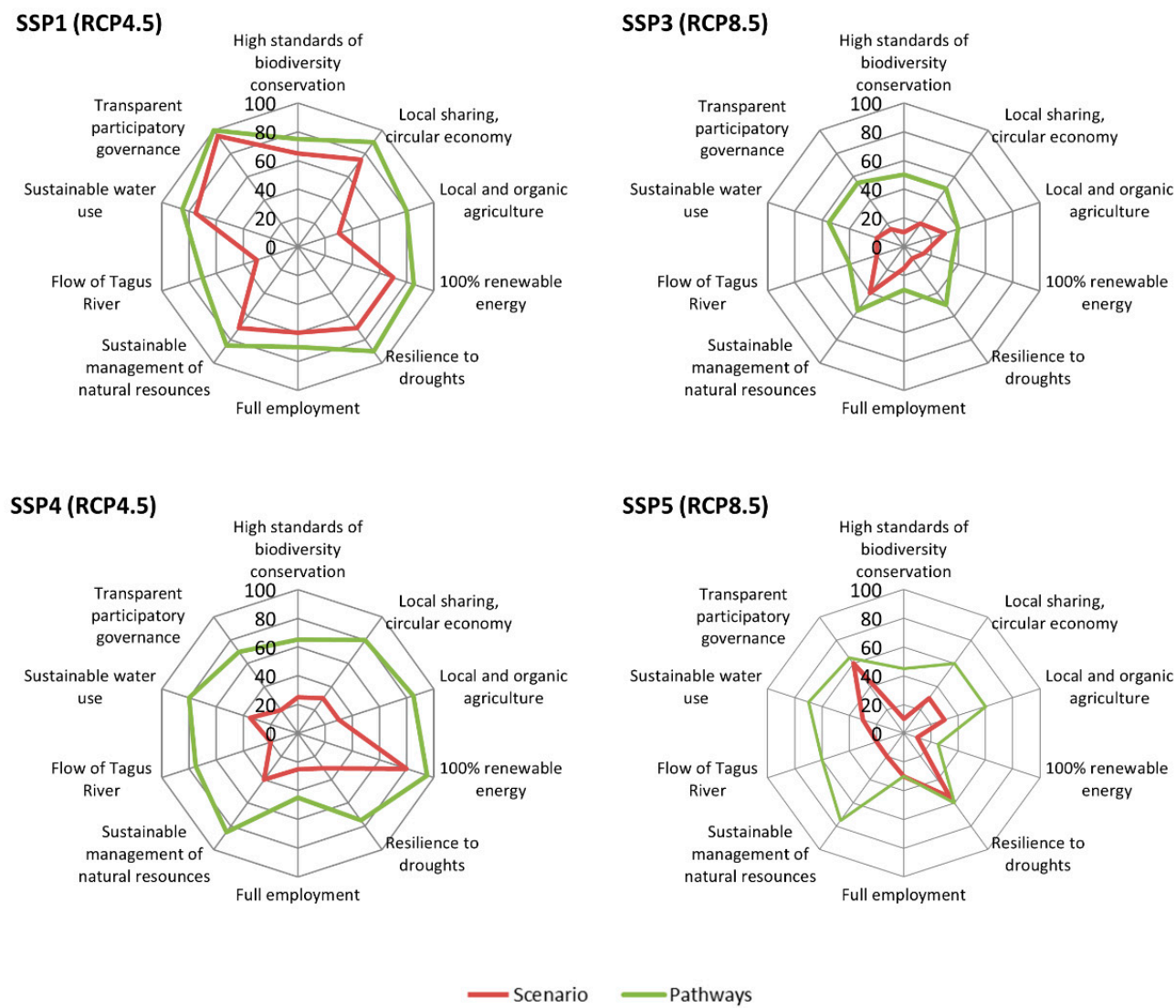

Figure 6. Comparison of Iberian Vision elements within scenarios and after implementation of the Pathways (value of 100 represents fully reaching the Vision).

\section{Discussion: The Role of Cross-Border Co-Operation}

The increasing scale, intensity and complexity of environmental problems reveal the limitations of existing governance institutions, both at national and regional levels, to address the new socio-ecological situation posed by HECC. The urgent challenges posed by climate change require the speedy design and implementation of institutional settings capable of making use of the best available and fit-for-purpose knowledge to support the management of complex problems emerging, often in an interrelated way, from different domains. Attaining such knowledge may require the construction of multi-scalar social action networks-rather than just data bases or information pools-in order to enhance the actual resilience and anticipatory capacities of social-ecological systems $[6,30,31]$. This is considered to favor institutional learning and more adaptive or, in our context, more transformative responses to fast environmental change [13,27,32-34]. 
Traditionally, policy science literature [35] has distinguished between horizontal, vertical and spatial integration (or socio-ecological fit). These different dimensions of policy integration are relevant in the case of HECC. The first dimension relates to the "mainstreaming" of sustainability and environmental considerations into overarching policy documents, sectors and local government policies, as well as strategic plans and budgets, and is formalized around the concepts of Environmental Policy Integration (EPI) and, in our case, "climate policy integration" [36-39]. The second dimension refers to the need to deploy suitable co-operation and control mechanisms between various levels of governance. Multilevel interaction and the existence of multiple sources of incentives and sanctions are decisive to guarantee the adequate governance of complex issues that relate to environmental change and sustainability. However, a third and crucial component relates to the fact that environmental problems do not necessarily coincide spatially with political jurisdictions. In our case, there is a clear need to build cross-border or trans-national institutional capacities capable of managing common environmental problems, such as those related to climate change. This is why we have also tried to look at the potential of existing agents to promote transformability in specific organizational arrangements [31,40-47].

Given the fast-changing socio-climatic conditions, especially for transboundary and regional development organizations, it is now clear that a more agile, attentive and adaptive approach to policy and governance is required. The implementation of the different EU and national environmental and cohesion policies acting upon the same cross-border territories in Portugal and Spain needs to take the new socio-economic and climate landscape into account. Different kinds of institutional synergies, as well as possible trade-offs, must be explored despite the large degree of uncertainty derived from a world going beyond $2{ }^{\circ} \mathrm{C}$. In the case of transboundary river basins, cross-border organizations can play a major role in co-ordinating complex national and regional institutional structures, which often involve various types of actors at different scales. For this reason, cross-border organizations-including Euroregions and Working Communities (WC)-have long been considered to have an important transformative power [46], with the potential not only for improving co-ordination across spatial scales but also for enhancing the local capacity of agents to better respond to increasing climate change risks [48-52].

In sum, cross-border organizations have a large potential for enhancing transformations and for mainstreaming climate change and sustainability concerns into national and regional policies, plans and programs $[14,53]$. They enable new agent capacities and skills -including those of policy entrepreneurship [19,54-56] — that focus on addressing common environmental problems at both sides of the border, "taking benefits from complementary assets, using synergies and critical masses to improve their competitive advantages as well as on co-ordination and integration objectives or coalition building" [57]. Due to their (spatial) proximities, such governance structures may contribute in a decisive way to join the forces of adjacent countries to combat common environmental issues in river basins. In the EU transboundary areas, new policy networks have appeared which no longer fit with the traditional divisions of nation-states, but are now created for achieving new co-operation goals and functional purposes. In addressing climate, water, energy, biodiversity or land use challenges, both political and non-political actors have sought to create new forms of policy arrangements able to address multiple domains in a synergetic manner. The current commitment of the UNFCCC in Paris to stay below $2{ }^{\circ} \mathrm{C}$ average (while aiming at $1.5^{\circ} \mathrm{C}$ ) global warming by the end of the century has pushed this demand for knowledge and cross-sectoral and institutional integration even further. However, little is known about its practical implications and the pathways of solutions needed to achieve that target at the regional and organizational levels. Based on the exploration of key institutional challenges and our results in terms of solution pathways, we can pinpoint several ways forward for successfully building institutional capacities and implementing transformative solutions to face HECC in Iberia. 


\section{Conclusions: Integrated Climate Governance under High-End Climate Change in Iberia}

This paper has sought to show a specific example of plural knowledge integration and elicitation of innovative solutions and strategies to support the Integrated Climate Governance (ICG) of transboundary river basins and cross-border regions in Europe under conditions of high-end climate change (HECC). In Iberia, four scenarios were co-created with stakeholders by downscaling and adapting the Shared Socio-Economic Pathways to the Portuguese and Spanish context. The overall goal of the newly-adapted SSPs in IMPRESSIONS was to be able to think in a multi-faceted way about transformations in various systems with special focus on water, land-use, agricultural and food systems and governance, and to explore which structural conditions and capacities could lead to positive fundamental systemic changes-'game changers'-according to a normative vision of the future of Iberia. In particular, we have demonstrated that unveiling different future socio-economic conditions, which in our case have depicted using various SSPs, can help anticipate the different capacities and policy options required to cope with HECC. For example, the potential risks and vulnerabilities in Iberia derived from a world going beyond $2{ }^{\circ} \mathrm{C}$ warming are likely to be more difficult to tackle, or will have to be dealt in rather different ways, in a more institutionally fragmented, un-coordinated future as depicted in the SSP3 scenario. In contrast, the capacities already deployed in a world which has already moved towards a more environmentally-friendly, policy-robust and socially-integrated common Iberian future, as represented by SSP1, may be not only more resilient to potential impacts derived from a high-end warming world, but also more likely to achieve a common vision aligned with sustainability and its required positive social-ecological transformations.

Both for research and policy action, a crucial challenge relates to how to develop new forms of institutional arrangements aligned with ICG in different plausible future situations. That is, and more specifically under HECC, an urgent quest for designing opportunity pathways and concrete options and solutions for transformation. Understanding and identifying possible options and pathways of solutions, according to different future socio-climatic scenarios, can improve the knowledge requirements and anticipate the needed transformative capacities for developing new forms of institutional arrangements better suited to address high-end climate change. Given that in this research we have taken an Iberian perspective, our focus has been on looking at the implications for specific organizations and agents already working within the two transboundary river basins of the Tagus and Guadiana and the cross-border EUROAAA and EUROACE Euroregions. On the one hand, the participatory appraisal process showed that all the pathways in the socio-economic scenarios supported the integrated, transboundary and cross-scale management of water resources as well as the strengthening institutional cooperation; but on the other, our results pointed out that depending on which different scenario contexts unfold in Iberia in the future, different kinds of institutional and governance capacities and clusters of transformative solutions may be needed to cope with a high-end climate world.

Acknowledgments: The research leading to these results has received funding from the European Community's Seventh Framework Program (FP7/2007-2013) under grant agreement No. 603416, IMPRESSIONS Project (IMPRESSIONS-Impacts and Risks from High-End Scenarios: Strategies for Innovative Solutions (www.impressions-project.eu). We would like to thank all the invited stakeholders at the Iberian workshops for their invaluable insights and Jill Jäger for her invaluable contribution.

Author Contributions: Simona Pedde, Katharina Hölscher and Kasper Kok and Niki Frantzeskaki worked on the overall participatory design, downscaling of SSPs and pathways identification. Empirical material collection, interviews and networking activities with stakeholders in Portugal and Spain were carried by Francesc Cots and Tiago Capela Lourenço. Anastasia Lobanova produced the hydrological modelling while policy analysis was carried out by Francesc Cots and John Etherington. Joan David Tàbara contributed to the knowledge integration of the Iberian case study and to most of the aforementioned tasks. However, this is truly a collaborative effort and many other members of the IMPRESSIONS project participated in all these tasks including the overall data collection, stakeholder facilitation and overall analysis.

Conflicts of Interest: The authors declare no conflict of interest. 


\section{References}

1. High-End Climate Change in Europe. 2017. Available online: www.impressions-project.eu (accessed on 8 January 2018).

2. Miller, T.R.; Wiek, A.; Sarewitz, D.; Robinson, J.; Olsson, L.; Kriebel, D.; Loorbach, D. The future of sustainability science: A solutions-oriented research agenda. Sustain. Sci. 2013, 9, 238-246. [CrossRef]

3. Nalau, J.; Handmer, J. When is transformation a viable policy alternative? Environ. Sci. Policy 2015, 54, 349-356. [CrossRef]

4. Patterson, J.; Schulz, K.; Vervoort, J.; van der Hel, S.; Widergerg, O.; Adler, C.; Hurlbert, M.; Anderton, K.; Sethi, M. Exploring the governance and politics of transformations towards sustainability. Environ. Innov. Soc. Transit. 2017, 24, 1-16. [CrossRef]

5. Berman, J.R.; Quinn, H.C.; Paavola, J. The role of institutions in the transformation of coping capacity to sustainable adaptive capacity. Environ. Dev. 2012, 2, 86-100. [CrossRef]

6. Tàbara, J.D.; St. Clair, A.L.; Hermansen, E.A.T. Transforming communication and knowledge production processes to address high-end climate change. Environ. Sci. Policy 2017, 70, 31-37. [CrossRef]

7. O’Neill, B.C.; Kriegler, E.; Riahi, K.; Ebi, K.; Hallegatte, S.; Carter, T.R.; Mathur, R.; van Vuuren, D. A new scenario framework for climate change research: The concept of shared socioeconomic pathways. Clim. Chang. 2014, 122, 387-400. [CrossRef]

8. Tàbara, J.D.; Roca, E.; Madrid, C.; Valkering, P.; Wallman, P.; Weaver, P. Participatory Integrated Sustainability Assessment of Water Systems. Lessons from the Ebro River Basin. Int. J. Innov. Sustain. Dev. 2008, 3, 48-69. [CrossRef]

9. Weaver, P.M.; Haxeltine, A.; Van De Kerkhof, M.; Tàbara, J.D. Mainstreaming action on climate change through participatory appraisal. Int. J. Innov. Sustain. Dev. 2006, 1, 238-259. [CrossRef]

10. Tàbara, J.D. Integrated Climate Governance and Sustainable Development. In European Research on Sustainable Development. Vol I: Transformative Science Approaches for Sustainable Development; Jaeger, C.C., Tàbara, J.D., Jaeger, J., Eds.; Springer and European Commission: Heidelberg, Germany, 2011; pp. 91-109.

11. Tàbara, J.D.; Ilhan, A. Culture as trigger for sustainability transition in the water domain: The case of the Spanish water policy and the Ebro river basin. Reg. Environ. Chang. 2008, 8, 59-71. [CrossRef]

12. Neto, S. Drivers for change in Water Policy: The Guadiana HELP Basin experience. J. Hydrol. Environ. 2011, $17,11$.

13. Cosens, B.; Gunderson, L.; Allen, C.; Harm Benson, M. Identifying Legal, Ecological and Governance Obstacles, and Opportunities for Adapting to Climate Change. Sustainability 2014, 6, 2338-2356. [CrossRef]

14. Cots, F.; Tàbara, J.D.; McEvoy, D.; Werners, S.; Roca, E. Cross-border organisations as an adaptive water management response to climate change: The case of the Guadiana river basin. Environ. Plan. C Politic Space 2009, 27, 876-893. [CrossRef]

15. Capela Lourenço, T.; João Cruz, M.; Carlsen, H.; Dzebo, A.; Tàbara, J.D.; Cots, F.; Haslett, J.; Harrison, P. Common Frame of Reference to Support the Understanding of Adaptation Decision-Making under High-End Scenarios. 2015. IMPRESSIONS Project Deliverable D1.1. Available online: http:/ /www.impressions-project.eu/documents (accessed on 8 January 2018).

16. Dzebo, A.; João Cruz, M.; Capela Lourenço, T.; Carlsen, H.; Dunn, M.; Cots, F.; Tàbara, J.D.; Juhász-Horváth, L.; Pintér, L. Assessment of Decision-Makers' Needs and Capacities, Drivers and Barriers for Using Scenarios, Modelling and Pathways Analysis Impressions Project Deliverable D1.2. 2015. Available online: http:/ / www.impressions-project.eu/documents (accessed on 8 January 2018).

17. Gramberger, M.; Zellmer, K.; Kok, K.; Metzger, M. Stakeholder integrated research (STIR): A new approach tested in climate change adaptation research. Clim. Chang. 2015, 128, 201-214. [CrossRef]

18. Hegger, D.; Lamers, M.; Van Zeijl-Rozema, A.; Dieperink, C. Conceptualising joint knowledge production in regional climate change adaptation projects: Success conditions and levers for action. Environ. Sci. Policy 2012, 18, 52-65. [CrossRef]

19. Kok, K.; Pedde, S. IMPRESSIONS Socio-Economic Scenarios. IMPRESSIONS Project Deliverable 2.2. Available online: http:/ / www.impressions-project.eu/documents/1/ (accessed on 8 January 2018).

20. Miller, C.A.; O'Leary, J.; Graffy, E.; Stechel, E.B.; Dirks, G. Narrative futures and the governance of energy transitions. Futures 2015, 70, 65-74. [CrossRef] 
21. Jordan, A.; Rayner, T.; Schroeder, H.; Adger, N.; Anderson, K.; Bows, A.; Le Quéré, C.; Joshi, M.; Mander, S.; Vaughan, N.; et al. Going beyond two degrees? The risks and opportunities of alternative options. Clim. Policy 2013, 13, 751-769. [CrossRef]

22. Van Vuuren, D.P.; Edmonds, J.; Kainuma, M.; Riahi, K.; Thomson, A.; Hibbard, K.; Hurtt, G.C.; Kram, T.; Krey, V.; Lamarque, J.F. The representative concentration pathways: An overview. Clim. Chang. 2011, 109, 5-31. [CrossRef]

23. Van Vuuren, D.; Kriegler, E.; O’Neill, B.C.; Ebi, K.L.; Riahi, K.; Carter, T.R.; Edmonds, J.; Hallegatte, S.; Kram, T.; Mathur, R.; et al. A new scenario framework for Climate Change Research: Scenario matrix architecture. Clim. Chang. 2014, 122, 373-386. [CrossRef]

24. Kok, K.; Pedde, S.; Gramberger, M.; Harrison, P.; Holman, I. New European socio-economic scenarios for climate change research: Operationalising concepts to extend the Shared Socioeconomic Pathways. Reg. Environ. Chang. 2017, submitted.

25. Wiek, A.; Iwaniec, D. Quality criteria for visions and visioning in sustainability science. Sustain. Sci. 2014, 9 , 497-512. [CrossRef]

26. Bielsa, J.; Cazcarro, I. Implementing Integrated Water Resources Management in the Ebro River Basin: From Theory to Facts. Sustainability 2015, 7, 441-464. [CrossRef]

27. Pahl-Wostl, C.; Conca, K.; Kramer, A.; Maestu, J.; Schmidt, F. Missing links in global water governance: A processes-oriented analysis. Ecol. Soc. 2013, 18, 33. [CrossRef]

28. Olsson, P.; Gunderson, L.; Carpenter, S.; Ryan, P.; Lebel, L.; Folke, C.; Holling, C.S. Shooting the rapids: Navigating transitions to adaptive governance of social-ecological systems. Ecol. Soc. 2006, 11, 18. [CrossRef]

29. Lobanova, A.; Liersch, S.; Tàbara, J.D.; Koch, H.; Hattermann, F.F.; Krysanova, V. Harmonizing human-hydrological systems under climate change: The case of the headwaters of the Tagus River. J. Hydrol. 2017, 548, 436-447. [CrossRef]

30. Folke, C.; Carpenter, S.R.; Walker, B.; Scheffer, M.; Chapin, T.; Rockström, J. Resilience thinking: Integrating resilience, adaptability and transformability. Ecol. Soc. 2010, 15, 20. [CrossRef]

31. Westley, F.R.; Tjornbo, O.; Schultz, L.; Olsson, P.; Folke, C.; Crona, B.; Bodin, Ö. A theory of transformative agency in linked social-ecological systems. Ecol. Soc. 2013, 18, 27. [CrossRef]

32. Fleming, A. Informing adaptation responses to climate change through theories of transformation. Glob. Environ. Chang. 2012, 22, 115-126.

33. Michaels, S.; Goucher, N.P.; McCarthy, D. Policy Windows, Policy Change, and Organizational Learning: Watersheds in the Evolution of Watershed Management. Environ. Manag. 2006, 38, 983-992. [CrossRef] [PubMed]

34. Gillard, R.; Gouldson, A.; Paavola, J.; Van Alstine, J. Transformational responses to climate change: Beyond a systems perspective of social change in mitigation and adaptation. Wiley Interdiscipl. Rev. Clim. Chang. 2016, 251-265. [CrossRef]

35. Lafferty, W.; Hovden, E. Environmental policy integration: Towards an analytical framework. Environ. Polit. 2003, 12, 1-22. [CrossRef]

36. Mickwitz, P.; Aix, F.; Beck, S.; Carss, D.; Ferrand, N.; Görg, C.; Jensen, A.; Kivimaa, P.; Kuhlicke, C.; Kuindersma, W.; et al. Climate Policy Integration, Coherence and Governance; Partnership for European Environmental Research (PEER): Leipzig, Germany, 2009.

37. Nunan, F.; Campbell, A.; Foster, E. Environmental Mainstreaming: The Organisational Challenges of Policy Integration. Public Adm. Dev. 2012, 32, 262-277. [CrossRef]

38. Tompkins, E.; Adger, W.N. Does adaptive management of natural resources enhance resilience to climate change? Ecol. Soc. 2004, 9. [CrossRef]

39. Urwin, K.; Jordan, A. Does public policy support or undermine climate change adaptation? Exploring policy interplay across different scales of governance. Glob. Environ. Chang. 2008, 18, 180-191. [CrossRef]

40. Brown, K.; O'Neill, S.; Fabricius, C. Social Science Understandings of Transformation. In The Complexity and Urgency of Global Environmental Change and Social Transformation, World Social Science Report 2013: Changing Global Environments; UNESCO Publishing: Paris, France, 2013; pp. 100-107.

41. Crona, B.; Bodin, O. Power Asymmetries in Small-Scale Fisheries: A Barrier to Governance Transformability? Ecol. Soc. 2010, 15, 32. [CrossRef] 
42. Ernstson, H. Transformative Collective Action: A Network Approach to Transformative Change in Ecosystem-Based Management. In Social Networks and Natural Resource Management: Uncovering the Social Fabric in Environmental Governance; Cambridge University Press: Cambridge, UK, 2011; pp. 1-24.

43. O'Brian, K. Global environmental change II: From adaptation to deliberate transformation. Prog. Hum. Geogr. 2012, 36, 667-676. [CrossRef]

44. Walker, B.; Holling, C.S.; Carpenter, S.R.; Kinzig, A. Resilience, adaptability and transformability in social-ecological systems. Ecol. Soc. 2004, 9, 5. [CrossRef]

45. Pahl-Wostl, C.; Becker, G.; Knieper, C.; Sendzimir, J. How multilevel societal learning processes facilitate transformative change: A comparative case study analysis on flood management. Ecol. Soc. 2013, 18, 58. [CrossRef]

46. Blatter, J. Beyond hierarchies and networks: Institutional logics and change in transboundary spaces. Governance 2003, 16, 503-526. [CrossRef]

47. Marshall, N.A.; Park, E.S.; Adger, N.W.; Brown, K.; Howden, M.S. Transformational capacity and the influence of place and identity. Environ. Res. Lett. 2012, 7, 034022. [CrossRef]

48. Van Kerkhoff, L.E.; Lebel, L. Coproductive capacities: Rethinking science-governance relations in a diverse world. Ecol. Soc. 2015, 20,1-14. [CrossRef]

49. Wolfram, M. Conceptualizing urban transformative capacity: A framework for research and policy. Cities 2016, 51, 121-130. [CrossRef]

50. Woodward, J. Overcoming systemic roadblocks to sustainability: The evolutionary redesign of worldviews, institutions, and technologies. Proc. Natl. Acad. Sci. USA 2009, 106, 2483-2489.

51. Ziervogel, G.; Cowen, A.; Ziniades, J. Moving from Adaptive to Transformative Capacity: Building Foundations for Inclusive, Thriving, and Regenerative Urban Settlements. Sustainability 2016, 8, 955. [CrossRef]

52. Feola, G. Societal transformation in response to global environmental change: A review of emerging concepts. Ambio 2015, 44, 376-390. [CrossRef] [PubMed]

53. McEvoy, D.; Cots, F.; Longdale, K.; Tàbara, J.D. The role of institutional capacity in enabling climate change adaptation. The case of the Guadiana river basin. In Transborder Environmental and Natural Resource Management, Proceedings of the International Symposium in Transborder Environmental and Natural Resource Management, Kyoto, Japan, 5-7 December 2007; De Jong, W., Snelder, D., Ishikawa, N., Eds.; Centre of Integrated Area Studies: Kyoto, Japan, 2010; pp. 49-60.

54. Huitema, D.; Meijerink, S. Realizing water transitions: The role of policy entrepreneurs in water policy change. Ecol. Soc. 2010, 15, 26. [CrossRef]

55. Huitema, D.; Mostert, E.; Egas, W.; Moellenkamp, S.; Pahl-Wostl, C.; Yalcin, R. Adaptive water governance: Assessing the institutional prescriptions of adaptive (co-)management from a governance perspective and defining a research agenda. Ecol. Soc. 2009, 14, 26. [CrossRef]

56. Perkmann, M. Policy entrepreneurship and multilevel governance: A comparative study of European cross-border regions. Environ. Plan. C Politic Space 2007, 25, 861-879. [CrossRef]

57. Sherer, R.; Zumbush, K. Limits for successful cross-border governance of environmental (and spatial) development: The Lake Constance Region. Procedia Soc. Behav. Sci. 2011, 14, 101-120. [CrossRef]

(C) 2018 by the authors. Licensee MDPI, Basel, Switzerland. This article is an open access article distributed under the terms and conditions of the Creative Commons Attribution (CC BY) license (http://creativecommons.org/licenses/by/4.0/). 